\title{
POVO AVÁ-CANOEIRO: EDUCAÇÃO ESCOLAR INDÍGENA E INTERCULTURALIDADE CRÍTICA ${ }^{1}$
}

LORRANNE GOMES DA SILVA ${ }^{2}$

$U E G, B R A S I L$

https://orcid.org/0000-0003-3760-3705

ELIAS NAZARENO ${ }^{3}$

$U F G, B R A S I L$

https://orcid.org/0000-0002-9689-9721

\begin{abstract}
RESUMO: O povo indígena Avá-Canoeiro está localizado em dois Estados brasileiros, em Goiás com uma família de 08 indígenas e em Tocantins onde vivem outras famílias com aproximadamente 22 indígenas. A pesquisa foi realizada com os Avá-Canoeiro de Goiás. O texto está organizado em duas análises. A primeira é sobre as tentativas de acesso à educação formal, e a segunda abordará o processo de constituição da Escola Indígena Ikatoté, que esteve pautado por uma proposta de Educação Escolar Indígena vinculada aos princípios pedagógicos da interculturalidade crítica, da diversidade linguística e do respeito aos processos próprios de aprendizagem, tendo em vista a realidade e a história desse povo. Para a efetivação dessa pesquisa foram realizadas diversas atividades de campo que contaram com a realização de entrevistas, oficinas e atividades de ordem didático-pedagógicas. Os resultados da pesquisa demonstraram que as dificuldades de acesso dos Avá-Canoeiro a uma educação diferenciada e intercultural, como assegura a Constituição de 1988 e a LDB (1996), continuam sendo enormes como pode-se observar nas diversas tentativas de criação da Escola Indígena Ikatoté ao longo dos últimos 20 anos.
\end{abstract}

PALAVRAS-CHAVE: Avá-Canoeiro, Educação Escolar Indígena, Interculturalidade Crítica.

ABSTRACT: The Avá-Canoeiro indigenous people are located in two Brazilian states, in Goiás with a family of 8 indigenous people and in Tocantins where other families live with approximately 22 indigenous people. The research was conducted with the Avá-Canoeiro of Goiás. The text is organized in two analyses, the first is about the attempts to access formal education, and the second will address the process of establishing the Ikatoté Indigenous School, which was based on a proposal of Indigenous School Education linked to the pedagogical principles of critical interculturality, linguistic diversity and respect for their own learning processes, taking into account the reality and history of this people. In order to carry out this research, several field activities were carried out, which included interviews, workshops, and didactic-pedagogical activities. The results of the research demonstrated that the difficulties of access of the Avá-Canoeiro to a differentiated and intercultural education, as guaranteed by the 1988 Constitution and the LDB (1996), continue to be enormous, as can be seen in the various attempts to create the Ikatoté Indigenous School over the last 20 years.

\footnotetext{
${ }^{1}$ Artigo Final do Estágio Pós-Doutoral pelo Programa de Pós-Graduação em História da Universidade Federal de Goiás, Goiânia (2019).

${ }^{2}$ Doutora em Geografia pela Universidade Federal de Goiás, Instituto de Estudos Socioambientais (IESA), Goiânia. Professora do curso de Graduação e Mestrado em Geografia da Universidade Estadual de Goiás (UEG), no campus Cora Coralina/ Cidade de Goiás/Brasil. E-mail: lorrannegomes@gmail.com

${ }^{3}$ Doutor em Sociologia pela Universidade de Barcelona (2003). Professor Associado II do curso de História e do curso de Educação Intercultural Indígena da Universidade Federal de Goiás, Goiânia. E-mail: eliasna@hotmail.com
} 
Espaço Ameríndio

KEYWORDS: Ava-Canoeiro, Indigenous School Education, Critical Interculturality. 
Espaço Ameríndio

\section{Introdução}

O povo Avá-Canoeiro está localizado em dois Estados brasileiros: uma família com 08 indígenas em Goiás e outra família com 22 indígenas aproximadamente em Tocantins.

Esse artigo é resultado de diversas pesquisas junto a família AváCanoeiro de Goiás, iniciada no mestrado (2010/2012) e doutorado (2013/2016) pela Universidade Federal de Goiás (UFG), Instituto de Estudos Socioambientais (IESA), Programa de Pós-graduação em Geografia e no pós-doutorado (setembro de 2018 a maio de 2019) pela UFG, Faculdade de História, quando novos trabalhos de campo foram realizados, sendo possível a atualização dos dados aqui apresentados.

O objetivo da pesquisa foi investigar os processos educacionais propostos e ou implementados para os Avá-Canoeiro de Goiás, até a criação da Escola Indígena Ikatoté. ${ }^{4}$ que tem como proposta basilar uma Educação Escolar Indígena pautada pela interculturalidade crítica, o plurilinguismo e o respeito aos espaços de aprendizagens pluriepistemológicos, diferenciados em conformidade com a realidade desse povo, bem como que tenha os Avá-Canoeiro como protagonistas da elaboração, execução e gestão de todo processo escolar.

O contato dos Avá-Canoeiro de Goiás com não-indígenas foi no ano de 1983, quando fizeram contato com um morador local e este contatou a Fundação Nacional do Índio (FUNAI), e tiveram sua terra demarcada. Como havia dois jovens, sempre houve a vontade deles em estudar, registrados em pedidos oficiais à FUNAI aqui apresentados. Portanto, é evidente que o direito à educação foi negado e negligenciado pelo estado e órgãos competentes. Isso causou tristeza e indignação dos indígenas, que sempre lutaram pela escola na aldeia e não tiveram apoio, nem políticas públicas adequadas para terem acesso à educação.

\section{Materiais e Métodos}

A abordagem desse estudo é qualitativa, quando a pesquisa busca interpretar de forma subjetiva os dados. Argumenta os resultados do estudo por meio de análises e percepções. Descreve o problema com interpretações mais subjetivas, tais como: sensações; pensamentos; opiniões; sentimento; percepções, entre outras. Conforme Moura e Lima (2014, p. 99) que:

A denominação qualitativa define-se por adentrar o mundo dos significados das ações e das relações humanas, que não são passíveis de formatar em números e equações, mas que se revestem de critérios de observação e análise, por meio das quais é possível desvendar seus sentidos e suas significações.

\footnotetext{
${ }^{4}$ Ikatoté significa na língua indígena Avá-Canoeiro algo que é bonito, bom. O nome da escola foi escolhido por Niwatxima Avá-Canoeiro.
} 
Os procedimentos metodológicos foram compostos pela observação participante, pautada por trabalhos de campo e rodas de conversas. Além disso, o levantamento bibliográfico teve a intenção de mapear pesquisas já realizadas sobre o tema e a análise de documentos foi necessária para a investigação de dados sobre os processos de implementação da educação junto aos Avá Canoeiro.

A compreensão de observação participante é embasada nos estudos de Goldenberg (1997, p. 63): "é uma metodologia de pesquisa que aparece como possibilidade na tentativa de descrição, explicação e compreensão do objeto de estudo". Para Ludke e André (1986), a vivência e a observação no lugar são consideradas fundamentais na pesquisa qualitativa e caracterizam-se pelo contato direto do pesquisador com os sujeitos. Oliveira $(2000$, p.24) ressalta ainda que é quando o:

O pesquisador assume um papel perfeitamente digerível pela sociedade observada, a ponto de viabilizar uma aceitação senão ótima pelos membros daquela sociedade, pelo menos afável, de modo a não impedir a necessária interação.

Sobre o trabalho de campo Minayo (2011) considera que ele permite que o pesquisador se aproxime da realidade sobre a qual formulou uma pergunta, mas também pode estabelecer uma interação com os sujeitos que conformam a realidade, construindo conhecimento empírico.

A roda de conversa é uma metodologia da pesquisa qualitativa que permite um tipo de discussão teórica e metodológica que é própria das ciências humanas, uma vez que seu campo de atuação, segundo Martins (1989), não é previamente definido. Para Moura e Lima (2014, p.99), a roda de conversa é:

no âmbito da pesquisa narrativa, uma forma de produzir dados em que o pesquisador se insere como sujeito da pesquisa pela participação na conversa e, ao mesmo tempo, produz dados para discussão. É, na verdade, um instrumento que permite a partilha de experiências e o desenvolvimento de reflexões sobre as práticas educativas dos sujeitos, em um processo mediado pela interação com os pares, através de diálogos internos e no silêncio observador e reflexivo.

Realizaram-se dois trabalhos de campo na aldeia do povo AváCanoeiro, no município de Minaçu/GO, para atualização dos dados. $O$ primeiro ocorreu de 14 a 20 de dezembro de 2018 , com estadia de 05 dias na aldeia, em que os aspectos gerais da Escola Indígena Ikatoté foram apresentados e dois dias em Minaçu, para analisar documentos da Escola na secretaria estadual.

O segundo trabalho de campo foi realizado de 03 a 10 de fevereiro de 2019 com estadia de 08 dias. Constituiu-se em investigar as atividades da Escola Indígena Ikatoté, bem como conversar com os professores e 
alunos sobre o andamento, dificuldades e perspectivas em uma roda de conversa. Além disso, o contato virtual com esse povo é permanente, podendo ser uma ferramenta para dúvidas, depoimentos, entre outras informações necessárias.

\section{Povo Avá-Canoeiro}

O povo Avá-Canoeiro foi até a década de 1970 denominado por "Canoeiros", por conta de sua grande habilidade de navegação, com suas ýagas 'canoas', de forma semelhante a outros povos indígenas que habitam e habitaram as margens dos rios e receberam denominação idêntica. Conforme Barbosa; Schmitz; Neto e Gomes (2014), organizados em aldeias, os Avá-Canoeiro mantinham uma forte relação com os rios. Canoeiros por excelência, deslocavam-se com facilidade, além da pesca ser uma prática cotidiana.

Os primeiros registros sobre os "Canoeiro", como eram conhecidos, são da primeira metade do século XVIII. Entretanto, evidências arqueológicas de ancestrais Tupi-Guarani, no Centro-Oeste do Brasil, apontam para a presença de prováveis Avá-Canoeiro no século XI e nos séculos XIV e XV na região (Schmitz; Wüst; Thies, 1982). A arqueologia levantada por Barbosa; (Schmitz; Neto e Gomes, 2014) considera em cerca de 600 anos a presença dos índios Avá-Canoeiro nas margens do rio Claro e do rio Araguaia em Goiás. André Toral aponta, no relatório da FUNAI (1983/V. 01, p.92), que:

São conhecidos, a nível nacional, por Avá-Canoeiro ou simplesmente canoeiro de Goiás. A população regional do meio norte goiano denomina-os de "Cara-preta". Essa denominação é utilizada contemporaneamente tanto para os grupos do Araguaia como para os do Tocantins.

Avá foi acrescentado ao nome quando da realização dos primeiros estudos linguísticos realizados depois do contato oficial (Harrison, 1974; Toral, 1984), uma vez que foram notadas semelhanças entre sua língua e línguas da família Tupi-Guarani, para as quais este termo funciona como autodenominação do grupo ou, simplesmente, constitui-se de um termo genérico para 'gente' ou 'pessoa'. De acordo com Silva (2005), os AváCanoeiro se consideram como awa 'gente' em oposição a maira/maila 'não indígena de pele clara'.

A estimativa demográfica mais antiga sobre esse povo, de acordo com Toral, (1984), é a de 1824, quando foi apontada a existência de trezentos "guerreiros". Os estudos de Moura (2006, p. 122) indicam um dado aproximado com o de Toral. Ela afirma que: "Antes da colonização do Brasil Central, os Avá deveriam ter aldeias com população não muito grande, possivelmente de 250 a 300 habitantes" na região GoiásTocantins.

Segundo Pedroso (1992), com a aproximação das frentes de expansão sobre a sua área de ocupação - o interflúvio das bacias dos rios 
Tocantins e Araguaia -, os Avá-Canoeiro passaram a ser perseguidos e sucessivamente massacrados, considerados "extintos" no fim do século XIX.

Como a maioria dos povos indígenas do Brasil, o povo Avá-Canoeiro tem sua história marcada por massacres e quase extermínio completo. Para Rodrigues (2013, p. 01): "O histórico dos Avá-Canoeiro e sua situação atual podem ser considerados como um dos mais dramáticos exemplos de opressão vivida por um povo indígena em solo brasileiro".

É certo que esse povo não aceitou a aproximação das frentes de expansão que avançavam sobre seu território e, desde então, passou a ser perseguido e massacrado. Os conflitos diretos entre os Avá-Canoeiro e os colonizadores datam, de acordo com estudos de Pedroso (1994), desde meados do século XVIII e chegam ao fim, aproximadamente, no século XX, sendo os conflitos mais acirrados os das décadas de 1940 e 1950, com uma drástica diminuição populacional. O massacre mais recente, registrado no norte do estado de Goiás, foi na década de 1960, na região conhecida por eles como mata do café. Extermínio organizado por fazendeiros locais, matando uma aldeia inteira, da qual sobreviveram apenas cinco indígenas.

O povo Avá-Canoeiro pertence ao sub-ramo IV da família TupiGuarani, tronco linguístico Tupi. A respeito da língua indígena AváCanoeiro, Borges (2006, p.24) afirma que "os estudos realizados sobre essa língua indígena brasileira são raros e os poucos que a pesquisam limitam-se a descrever alguns aspectos fonético-fonológicos ou a apresentar algumas listas de palavras". Para Borges (2006, p. 26), a língua Avá-Canoeiro "é uma língua altamente ameaçada de extinção, devido ao reduzido número de falantes, e praticamente sem documentação disponível e estudos feitos".

Depois dos massacres sofridos e de todo o processo de dispersão espacial, os Avá-Canoeiro estão divididos em duas famílias (MAPA 01), contatados oficialmente na segunda metade do século XX - os AváCanoeiro que vivem no Estado do Tocantins, cujo contato ocorreu em 1973/1974 e que somam aproximadamente 22 indígenas; e os AváCanoeiro que vivem no Estado de Goiás (08 indígenas), cujo contato ocorreu em 1983.

Separados há quase dois séculos, Borges (2006) considera que os Avá-Canoeiro do Tocantins e do Araguaia desenvolveram histórias distintas e com diferenças culturais consideráveis. Para Rodrigues (2013, p.01), “Os Avá-Canoeiro do rio Araguaia possuem uma história diferenciada e se distinguem etnicamente dos Avá-Canoeiro do rio Tocantins, embora os dois grupos se autodenominem Ãwa". 
Figura 1 - Localização da Terra Indígena Avá-Canoeiro em Goiás e família AváCanoeiro do Tocantins
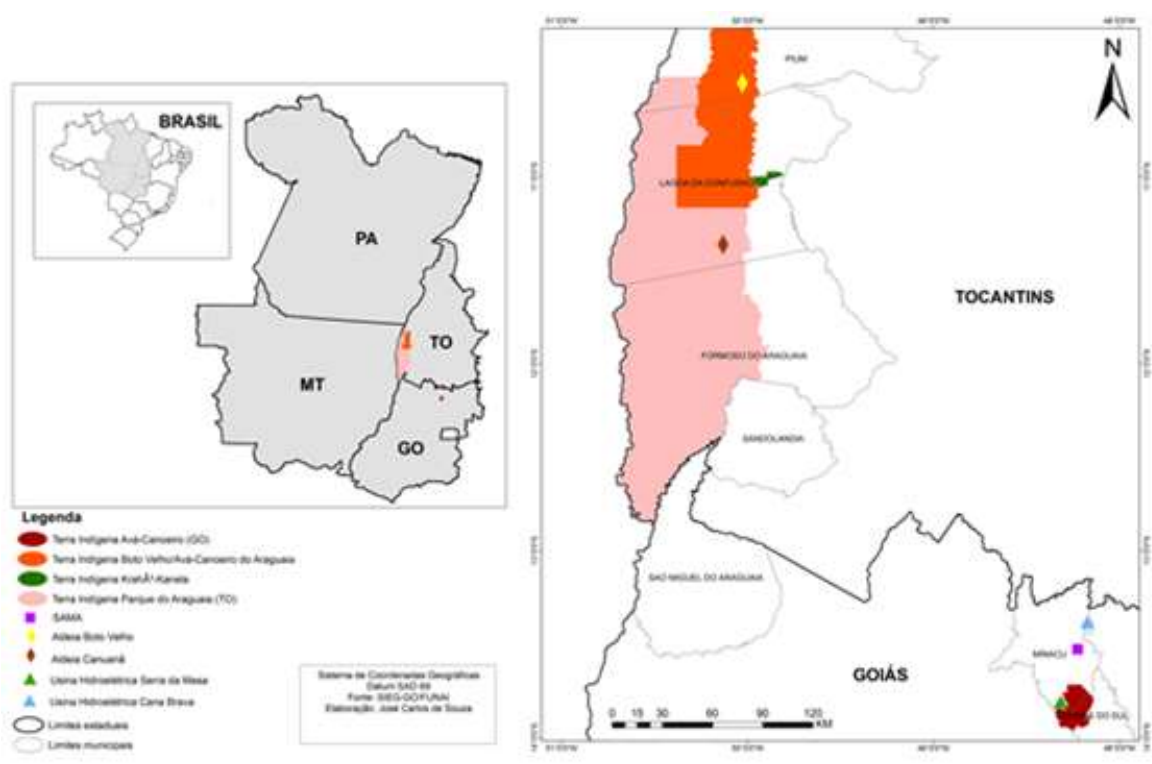

Fonte: SILVA, Lorranne Gomes da. Tese (2016).

O presente estudo é referente à família ${ }^{5}$ Avá-Canoeiro que vive no Estado de Goiás. A Terra Indígena Avá-Canoeiro está situada precisamente nos municípios de Minaçu e Colinas do Sul - no extremo norte do Estado de Goiás, pertencendo à mesorregião do Norte goiano e a microrregião de Porangatu, a 510 km de Goiânia (via Nerópolis) e a 445 km de Brasília (via Barro Alto).

A área da Terra Indígena Avá-Canoeiro, que ainda está em processo de homologação, é de 38 mil hectares ao longo do córrego Pirapitinga, na margem esquerda do rio Tocantins, a $14 \mathrm{~km}$ da jusante da Usina de Serra da Mesa (administrada por FURNAS Centrais Elétricas) e a $10 \mathrm{~km}$ da Usina Hidrelétrica de Cana Brava (administrada pelo grupo Tractebel Suez).

Os Avá-Canoeiro vivem em um território permeado por interesses de empreendimentos empresariais de várias ordens, presentes no Cerrado do norte goiano, sobretudo, pelo hidronegócio ${ }^{6}$, evidenciado pelas Usinas Hidrelétricas de Cana Brava e Serra da Mesa, além de projetos de mineração.

Conforme Almeida (2005), a Usina Hidrelétrica de Serra da Mesa formou um lago (o maior do Brasil em volume de água), que ocupa uma área maior que da cidade de São Paulo $\left(1.784 \mathrm{Km}^{2}\right)$, com 54,4 bilhões de $\mathrm{m}^{3}$. Chega a atingir 70 metros de profundidade e inundou partes dos municípios de Niquelândia, Santa Rita do Novo Destino, Minaçu, Uruaçu, Campinorte, Campinaçu, Colinas do Sul e Barro Alto, todos situados no

\footnotetext{
${ }^{5}$ Conforme estudos de Silva (2005), será utilizado o termo "família” não como uma separação biológica, de parentesco, mas no sentido de ser um termo que apresenta melhor a afetividade do convívio cotidiano, por serem grupos pequenos e por haver certa aliança entre eles na constituição da família.

${ }^{6}$ Conforme Malvezzi (2012, p. 397), o hidronegócio é "literalmente, o negócio da água, e tem óbvia inspiração na expressão agronegócio". Por isso ser comum o uso do termo agro hidronegócio.
} 
Norte e Nordeste Goiano. Foi um dos empreendimentos técnicoeconômicos que provocou alagamento de áreas, expropriação de pessoas e modificação drástica na paisagem.

Entre os danos causados na Terra Indígena Avá-Canoeiro, estão a inundação da área de aproximadamente 3.163 hectares, que corresponde, em média, a $10 \%$ do território; a abertura de estradas e linhas de transmissão; retirada de material argiloso para edificação da barragem e a barragem propriamente dita, com diques de contenção que também estão no interior da Terra Indígena; além da modificação da paisagem com as redes, fios e postes de energia.

Conforme Silva (2016), em compensação à "invasão" da Usina Hidrelétrica na Terra Indígena Avá-Canoeiro, criaram-se os convênios de Furnas ${ }^{7}$, com a Fundação Nacional do Índio (FUNAI), pautados no Programa de Assistência Avá-Canoeiro (PAAC) e no repasse em Royalties (PCIAC). O PAAC é deliberado por convênios, sendo que os primeiros foram de $n^{\circ} 023 / 1986$ e $n^{\circ} 10.323 / 1992$ e o último foi assinado em 2012, com duração de cinco anos e possibilidade de prorrogação. Todos ativos em 2019.

Cada um tem valor aproximado de seis milhões de reais, sendo que mais de dois milhões estão destinados à fiscalização e vigilância contratada diretamente por Furnas, o restante é dividido em programas que deverão ser realizados pela FUNAI. De acordo com a FUNAI, todo o repasse recebido pelo órgão vai para a "Renda Indígena" ${ }^{8}$ e deve ser executado por meio da lei federal 8.666, com todas as exigências e burocracias, que muitas vezes inviabilizam a execução dos recursos. Já o PCIAC é um pagamento mensal, por tempo indeterminado, equivalente a $2 \%$ do valor a ser distribuído a título de royalties ${ }^{9}$ aos Avá-Canoeiro e aos municípios inundados.

\section{Processos Educacionais: Povo Avá-Canoeiro}

Os dados aqui apresentados constam nas documentações e registros da Regional da FUNAI/CTL, localizada na cidade de Minaçu, e no relatório organizado por Silva, Silveira e Guedes (2014).

A primeira menção sobre educação escolar no âmbito da Terra Indígena Avá-Canoeiro se deu por meio de um pedido formal do Posto

\footnotetext{
${ }^{7}$ É uma empresa brasileira de economia mista subsidiária da Eletrobrás, vinculada ao Ministério de Minas e Energia, atuando no segmento de geração e transmissão de energia em alta e extra alta tensão.

${ }^{8}$ Tem como finalidade gerir os recursos e os bens patrimoniais oriundos de projetos e programas que atendem a determinados povos indígenas que foram compensados e/ou indenizadas com recursos originários de doações, leilões e Planos Básicos Ambientais como forma de mitigar ou compensar os impactos socioambientais causados por empreendimentos que impactam terras e os povos indígenas. A execução físico-financeira e os controles administrativos da gestão do patrimônio indígena são exercidos pela FUNAI, pois compreende-se que não há força de trabalho ou estrutura física específica para a Renda. Fonte: http://www.cgu.gov.br. Acesso: maio de 2019.

${ }^{9}$ Uma das formas mais antigas de pagamento de direitos. São aplicados quando o assunto é recurso energético, como o petróleo e o gás natural, sendo uma compensação financeira que as empresas exploradoras e produtoras desses bens não renováveis devem ao Estado e cujo pagamento é feito mensalmente. Disponível em: https://www.significados.com.br/royalties. Acesso: 23 de agosto de 2019.
} 
Indígena (PIN) ${ }^{10}$ Avá-Canoeiro (Minaçu) à sede da FUNAI, em Brasília, em 1998. O pedido solicitava a implementação de um programa de educação para dois jovens Avá-Canoeiro, Trumak e Niwatima, com idade entre 10 e 12 anos.

Em 1999, foi firmada uma parceria da FUNAI com a Universidade Federal de Goiás (UFG) para a realização de um projeto de Educação Escolar para os Avá-Canoeiro (Intitulado - Povo Avá-Canoeiro: Educação, revitalização da língua e cultura), com início em 2000, enfocando o ensino do português e o registro da língua Avá-Canoeiro.

Durante os anos de 2000 a 2003, foram realizadas algumas das etapas e subprogramas do supracitado projeto, bem como encaminhados à FUNAI os relatórios trimestrais de atividades. No entanto, nos anos de 2003 e 2004, o projeto de educação foi interrompido pelo chefe do PIN Avá-Canoeiro/FUNAI sem a devida apresentação de justificativas.

De 2004 a 2006, não houve avanços e tampouco ações referentes à Educação Escolar Indígena junto aos Avá-Canoeiro. Apenas em abril de 2006, os pedidos dos Avá-Canoeiro para estudarem na aldeia, sobretudo de Trumak e Niwatima, foram reiterados. Em 2006, a secretaria de educação local, junto com os Avá e a FUNAI, aprova, em Minaçu, a criação da Escola Municipal Indígena na aldeia Avá-Canoeiro no âmbito da Educação Básica do Sistema Municipal de Ensino de Minaçu, a qual previa a contratação de uma professora para atuar na aldeia no ensino de português. A contratação foi efetivada, mas a criação da escola não ocorreu, por motivos não justificados.

No final de 2007, iniciaram-se novamente as discussões para a criação da Escola Indígena Avá-Canoeiro, desta vez como uma extensão de uma unidade escolar da Cidade de Minaçu. Devido ao baixo número de alunos, a escolarização dos indígenas passou a ser da competência do estado, conforme o Ofício 392/2007, de 11 de dezembro de 2007, já que era necessário atender a educação infantil, ensino fundamental e médio.

Em 2009, observa-se que o apoio institucional que era oferecido pelo município de Minaçu não se concretizou na esfera estadual. Desse modo, a educação continuou informal. Em meados de 2009, há registros de conflitos entre os estudantes Avá-Canoeiro e a professora contratada, tendo esta, então, o seu contrato cancelado.

Em 2010 e 2011 , nada de novo ocorreu ao se tratar da Educação Escolar Indígena para os Avá-Canoeiro. O processo é retomado em 2012, após a reestruturação da FUNAI, com a lei $n^{0} 12.593^{11}$. Foi solicitada pela Coordenadoria Local CTL de Minaçu à Universidade de Brasília uma assessoria linguística junto aos Avá-Canoeiro para catalogar e registrar a língua dos indígenas. A universidade atendeu ao pedido e foi elaborado - "Projeto de Assessoria Linguística junto aos Avá-Canoeiro", com vigência de 2012 a 2014 . Conforme Silva e Silva (2018, p.92,93):

\footnotetext{
${ }^{10}$ Nomeada a posteriori por Coordenadoria Técnica Local (CTL).

${ }^{11}$ A Lei $\mathrm{n}^{\mathrm{o}} 12.593$, de 18 de janeiro de 2012, que institui o Plano Plurianual da União para o período de 2012 a 2015, prevê sob a responsabilidade da Fundação Nacional do Índio o Programa de Proteção e Promoção dos Direitos dos Povos Indígenas. Disponível em: http://www.funai.gov.br/index.php/planoplurianual-ppa/2012-2015. Acesso: 21 de agosto de 2019.
} 
O projeto possibilitou a atualização do diagnóstico sociolinguístico de vitalidade da língua Avá-Canoeiro, um primeiro mapeamento de processos de aprendizagem tradicionais dos Avá-Canoeiro, com vistas a contribuir na elaboração e execução de projetos de educação indígena, em parceria com os próprios Avá-Canoeiro; primeiras observações acerca de questões sociais e culturais que possibilitariam a prestação de melhor assessoria linguística à FUNAI; e o aprofundamento da descrição linguística da língua Avá-Canoeiro por meio de uma dissertação de mestrado, realizada entre 2013 e 2014, intitulada "Elementos de Fonologia, Morfossintaxe e Sintaxe da Língua Avá-Canoeiro".

Em 2014, a pedido da CTL/Minaçu, foi constituído um Grupo de Trabalho sobre a Educação Avá-Canoeiro, composto por um pesquisador linguista da UnB, uma servidora antropóloga da FUNAI e uma pesquisadora antropóloga colaboradora, com o objetivo de realizar um levantamento documental e oral junto aos Avá-Canoeiro e diagnosticar os motivos do insucesso dos processos educacionais realizados anteriormente.

Esse grupo ressaltou no relatório apresentado para a FUNAI e Secretaria de Educação e Cultura do Estado de Goiás (SEDUC) o pouco desenvolvimento dos indígenas quanto à produção de conhecimento na língua portuguesa. Seria emergencial implementar uma escola na aldeia ou viabilizar que eles estudassem em Minaçu, já que era um desejo deles frequentar a escola. Destacou-se também a falta de interesse da FUNAI em contribuir para a efetivação da escola na Terra Indígena Avá-Canoeiro, justificada pelo descumprimento da colaboração de transporte para a professora Guiomar Pereira até a aldeia, oferecida em reuniões com a SEDUCE e os indígenas.

Em 2015, a CTL/Minaçu informou oficialmente à SEDUC sobre a necessidade de implementação de educação escolar diferenciada e específica para os Avá-Canoeiro, uma vez que a mesma havia sido interrompida desde 2009. Havia nesse período muitos pedidos dos AváCanoeiro em estudar e poder ter uma escola. Conforme disse Trumak Avá-Canoeiro: "Eu quero estudar, aprender a ler, escrever, tirar minha carteira de motorista, ser policial e dirigir um caminhão. Não quero estudar em Minaçu, não gosto daquela escola, quero escola aqui na aldeia, isso já falei com a minha irmã Niwatima. (TRABALHO E CAMPO, 2015)".

Ainda em 2015, foi constituído pela SEDUC, através da Coordenação de Educação Escolar do Campo Indígena, um Grupo de Trabalho para colaborar voluntariamente nas discussões, formação e implementação de uma extensão escolar pautada nos princípios da Educação Escolar Indígena para os Avá-Canoeiro.

O grupo de trabalho, a princípio, foi composto pelos indígenas AváCanoeiro e Tapirapé; pela FUNAI, tendo como representante uma antropóloga em serviço; por servidores da SEDUC/Coordenação de 
Educação Escolar do Campo Indígena; da Subsecretaria Estadual de Educação da Cidade de Minaçu; um linguista da Universidade de Brasília (UNB); um linguista da Universidade Federal de Goiás (UFG); uma antropóloga da UFG e uma geógrafa da Universidade Estadual de Goiás (UEG), campus Cora Coralina.

O Grupo de Trabalho teve a oportunidade de realizar reuniões na Terra Indígena Avá-Canoeiro junto às instituições responsáveis pela educação dos Avá-Canoeiro, com o fim de elaborar um projeto de educação diferenciada e específica que de fato contemplasse as necessidades, desejos e anseios dos Avá-Canoeiro e Tapirapé, na T.I AváCanoeiro.

Vários temas foram discutidos, como a cooperação entre as instituições partícipes na elaboração da proposta pedagógica, do projeto político pedagógico e a atenção especial ao contexto cultural da realidade trilíngue da comunidade indígena, com falantes de Avá-Canoeiro; Tapirapé ${ }^{2}$ e Português.

Em maio de 2016, depois de reuniões e muitas discussões junto aos Avá-Canoeiro e Tapirapé, a Extensão Escolar Indígena Ikatoté foi criada na Terra Indígena Avá-Canoeiro ${ }^{13}$. Dois documentos foram importantes norteadores em relação à educação formal entre os AváCanoeiro, quais sejam a Lei $n^{\circ} 14.812$, de 06 de julho de 2004, e o Ofício de $n^{\circ} .015 / 2005$, da SEDUC.

O primeiro trata da criação da Escola Avá-Canoeiro na Terra Indígena Avá-Canoeiro. O segundo informa que a escola Avá-Canoeiro não tinha sido implantada, alegando que a população se resumia a 06 (seis) pessoas, sendo 02 (dois) jovens, que eram atendidos por projetos desenvolvidos pela Pontifícia Universidade Católica de Goiás - PUC e FUNAl. Novamente, não fora possível a criação de uma escola nesse momento por conta do quantitativo de alunos e funcionários insuficientes, apesar de ser esse um dos anseios maiores do Grupo de Trabalho.

É interessante notar que, em 2019, o público escolar é bastante diferente daquele de duas décadas atrás. Os jovens Avá-Canoeiro daquela época possuíam entre vinte e trinta anos. Atualmente, uma nova geração, composta por três crianças, começa a surgir. Além disso, o projeto de escola diferenciada e específica esboçada pelo Grupo de Trabalho busca contemplar também as necessidades educacionais dos Avá-Canoeiro mais velhos, Niwatima disse que:

Todo mundo precisa de escola aqui na aldeia, meus filhos, meu marido, meu irmão, todos. Nakwatxa gosta de ficar na escola, desenha, assiste as aulas e participa

\footnotetext{
12 Niwatima Avá-Canoeiro casou-se com Parazinho Tapirapé e tiveram três filhos. Desse modo, a língua tapirapé é também presente no cotidiano dessa família.

${ }^{13}$ Uma extensão escolar funciona de acordo com a Unidade Escolar que a rege - no caso da extensão da Escola Indígena Ikatoté é a Escola Estadual Ministro Santiago Dantas, sediada na cidade de Minaçu a aproximadamente $30 \mathrm{~km}$ da aldeia. Portanto, a extensão tem Projeto Político Pedagógico bem como uma proposta de Educação Escolar específica para o povo indígena; só que quem rege os assuntos financeiros, presta contas, redireciona os valores, emite documentação de secretaria - como, por exemplo, transferência, matrícula, entre outros - é a unidade escolar na qual a extensão está vinculada.
} 
quando interessa, Tuia vem fazer tapete na escola. Elas têm muito para ensinar e são professoras também, tem que fazer aula de conhecimento delas, que sabe mais que a gente. (TRABALHO DE CAMPO, 2015)

As contratações realizadas pela SEDUC/GO, com consentimento dos Avá, buscaram contemplar o estudo das três línguas: Ava-Canoeiro, Tapirapé e Português. Para isso, foram contratados, inicialmente, um professor de língua Tapirapé e uma professora de língua portuguesa e, posteriormente, uma indígena Avá-Canoeiro foi contratada como professora de sua língua materna.

Por motivos pessoais e de gestão, sobretudo da FUNAI, o primeiro professor da língua Tapirapé contratado permaneceu na aldeia apenas um ano e meio, sendo substituído por outro professor Tapirapé, que ficou por seis meses, aproximadamente (não há condições adequadas para manter esses professores e sua família na aldeia, é visível a falta de interesse dos gestores locais para promover a permanência deles). Desse modo, em 2019, reconfigurou-se o contrato de professores, tendo hoje Parazinho como professor da língua Tapirapé; Niwatima como professora da língua Avá-Canoeiro e diretora da escola; e a professora Guiomar de Língua portuguesa, todos contratados pela SEDUC.

A extensão escolar oferece Ensino de Jovens e Adultos (EJA) para os adultos Avá-Canoeiro (Niwatima, Trumak, Matxa, Nakawtxa e Tuia) e Parazinho Tapirapé, além de Ensino Fundamental para o Patxeo, filho mais velho de Niwatima com Parazinho. Mesmo depois da criação da Extensão Escolar Ikatoté, o grupo de trabalho ainda atua como equipe técnica de apoio e acompanhamento. A representante da FUNAl se aposentou e não faz mais parte da equipe.

O grupo de trabalho colabora com a formação dos professores; com a produção e publicação de materiais didáticos; na elaboração do Projeto Político Pedagógico (PPP) ainda em construção, que atenda os princípios da Educação Escolar Indígena diferenciada e específica, multilíngue e intercultural, com matriz curricular e calendário específicos; entre outras demandas. O grupo de trabalho, assim como os Avá-Canoeiro/Tapirapé, anseia por uma escola definitiva na aldeia com recursos próprios e gestada por eles.

\section{Resultados e Discussão: Educação Escolar Indígena e Interculturalidade Crítica}

Conforme dados do IBGE (2010), existem no Brasil cerca de 305 povos indígenas, aproximadamente 896,9 mil pessoas, 732 Terras Indígenas, 274 línguas. A FUNAI (2019) também registra 70 povos isolados e 82 referências de índios ainda não contatados, além de existirem grupos que estão requerendo o reconhecimento indígena.

Os estudos de Cunha (1992) apontam que esses grupos sociais, através do critério étnico e o uso político de sua identidade diferenciada em relação aos demais segmentos da população de um país, são um 
marco no século XX. Neste sentido, a luta indígena pelo direito aos seus territórios e reprodução sociocultural, culminou com conquistas jurídicas seculares, como, por exemplo, o direito à Educação Escolar Indígena.

Por séculos a educação oferecida para os indígenas no Brasil era planejada, instituída, executada e gerida pela sociedade não indígena. Desde os missionários jesuítas até os positivistas do Serviço de Proteção aos Índios (SPI). A ideologia era um ensino autoritário, catequético e disciplinar, que contribuía muito mais para negar as diferenças e particularidades culturais desses povos, marcando o fortalecimento de valores que negavam as identidades, línguas e modos de vida considerada como uma educação indígena excludente e violenta. Um posto do SPI em cada Terra Indígena e em cada posto uma escola conforme Souza Lima (1995, p.191) que:

Tratava-se, pois, de noções elementares da língua portuguesa (leitura e escrita) e estímulo ao abandono das línguas nativas, além de se introduzir uma série de pequenas alterações no cotidiano de um povo indígena, a partir de formas de socialização características de sociedades que têm na escola seu principal veículo de reprodução cultural. O modelo de governo idealizado, e que foi em certos casos com certeza implementado, procurava atingir a totalidade das atividades nativas, inserindo-se em tempos e espaços diferenciados dos ciclos, ritmos e limites da vida indígena.

Segundo Bhabha (1998), a visibilidade da mumificação cultural na ambição declarada do colonizador de civilizar ou modernizar o nativo, resulta em instituições arcaicas inertes (que funcionam) sob a supervisão do opressor.

Sabe-se que da substituição do SPI que ocorreu em 1967, quando foi criada a Fundação Nacional do Índio (FUNAI), com pequenas mudanças e avanços), contra essa realidade opressora que envolvia esses povos, surgiram os movimentos indígenas nacionais e internacionais que, desde então, tem tido uma atuação permanente com apoio de ONGs, Universidades e outras instituições, na reinvindicação pelo direito à diferença, à terra, à saúde e à educação diferenciada.

A Constituição de 1988 rompeu um paradigma legitimado pelas Constituições anteriores que objetivavam a integração dos indígenas à sociedade nacional por meio da aniquilação das diferenças. Essa conquista legal propiciou que a Educação Escolar Indígena fosse garantida no Brasil pela Constituição Federal de 1988; pela Lei de Diretrizes e Bases 93.94/96; pelas Diretrizes da Educação Escolar Indígena de 1998; pela Resolução n 5 de 2012 e no parecer 14/99 do Conselho Nacional da Educação.

No século XXI, sobretudo a partir da década de 1970, experiências surgiram em várias regiões do Brasil, construindo projetos educacionais específicos às realidades socioculturais e históricas de povos indígenas. Entretanto, a introdução da Educação Escolar Indígena em Terras Indígenas, insere-se em um processo mais amplo de organização e luta - 
mesmo sendo almejada por eles e garantida por leis não ocorre sem conflitos.

A Educação Escolar Indígena tem como objetivo quebrar 0 paradigma positivista e superar práticas homogeneizadoras, disciplinares, etnocêntricas, nacionalistas, exacerbadas, discriminatórias que negam as especificidades de cada sujeito ou grupo social. Para esse fim, conforme Candau (2012), utiliza-se de políticas de igualdade e de reconhecimento da diversidade referidas à educação escolar. Segundo as Diretrizes para a Política Educacional de Educação Escolar Indígena (1994, p. 12):

\begin{abstract}
A escola indígena tem como objetivo a conquista da autonomia socioeconômico cultural de cada povo, contextualizada na recuperação de sua memória histórica, na reafirmação de sua identidade étnica, no estudo e valorização da própria língua e da própria ciência - sintetizada em seus etno-conhecimentos, bem como no acesso às informações e aos conhecimentos técnicos e científicos da sociedade majoritária e das demais sociedades, indígenas e não-indígenas.
\end{abstract}

As experiências a respeito da Educação Escolar Indígena AváCanoeiro são recentes. O modelo de escola e ensino ainda estão em construção. Portanto, considera-se que há um esforço em efetivar uma educação pautada na realidade plurilíngue, respeitando os espaços pluriepistemológicos e pautada na interculturalidade crítica $^{14}$ como um processo e/ou projeto social, político, ético e epistêmico, entendido como resiliência, desobediência e proposição alternativa à perspectiva epistemológica ocidental, que traga à superfície saberes e narrativas outras que foram historicamente negligenciadas e subalternizadas. Segundo Nazareno (2017, p. 46):

A interculturalidade crítica, entendida como processo social, político e epistêmico, pode ser considerada, portanto, como sinônimo da decolonialidade, pois mesmo tendo em conta as relações assimétricas estabelecidas pelo colonizador em termos políticos, sociais e epistêmicos, não há como negar a influência recíproca exercida por parte daqueles que foram historicamente subalternizados. Nesse sentido, a decolonialidade instala-se no mesmo momento em que se instala a colonialidade do poder. Os povos indígenas que permanecem vivos, com seus conhecimentos e suas línguas, são uma prova viva da decolonialidade como processo de resistência e afirmação identitária.

\footnotetext{
${ }^{14}$ Nazareno (2016, p.3), aponta que a reescrita da história dos contatos pelo viés da decolonialidade e da interculturalidade crítica considera os povos indígenas como copartícipes dela, ao contrário da escrita historiográfica vigente que, "quando muito, [os considera] como coadjuvantes de uma história que, ao prescindir deles, não existe de fato".
} 
Os elementos apresentados que constituem o pensar de uma Educação Escolar Indígena estão presentes na realidade do Colégio Estadual Avá-Canoeiro Ikatoté do povo Avá-Canoeiro, que por décadas teve o direito à educação negada e negligenciada. Disse a diretora da Escola Ikatoté:

Muito tempo queremos escola aqui na aldeia, mas ninguém escuta esse pedido da gente, muita gente já passou aqui, fala que vai ter, mas vem um professor fica aqui vai embora, vem outro e assim que é. Meu irmão não deu certo com a professora, fica assim, vai embora, nunca mais volta, não fala nada. Agora estou vendo que é verdade, temos escola, temos professores, aprendemos nossa língua e língua portuguesa e Tapirapé, ensinamos as crianças do nosso jeito, no nosso tempo, tem lanche para elas, tem materiais, mas ainda falta muita coisa. Queremos uma escola do nosso povo, Avá-Canoeiro, agora podemos lutar para isso (RODA DE CONVERSA, 2019).

O PPP do Colégio Estadual Avá-Canoeiro Ikatoté, ainda em construção coletiva com os indígenas, pauta-se em matriz curricular, calendário e ensino específico e diferenciado, conforme o documento:

O Colégio Estadual Avá-Canoeiro Ikatote, Ensino Fundamental de $1^{\circ}$ ao 90 ano, Ensino Médio e EJA tem por finalidade através deste Regimento, assegurar a unidade filosófica, político, pedagógica, estrutural e funcional desta Unidade Escolar, garantindo a Educação Escolar Indígena diferenciada, específica, plurilíngue, comunitária e intercultural nos processos próprios educativos pedagógicos da educação escolar indígena, enquanto instrumento indispensável à execução de uma política educacional para Rede Pública em consonância com Constituição Federal de 1988, Lei de Diretrizes e Bases 93.94/96; as Diretrizes da Educação Escolar Indígena 1998; a Resolução no 5 de 2012 e no parecer 14/99 do Conselho Nacional da Educação no que se trata da Educação Escolar Indígena da Câmara Básica de Educação (PPP, 2016).

De acordo com os princípios da Educação Escolar Indígena (PPP), que norteiam sua ação educativa, o Colégio Estadual Avá-Canoeiro Ikatoté propõe as seguintes metas:

Proporcionar aos estudantes Avá-Canoeiro, valorização dos seus saberes, acesso às informações, conhecimentos técnicos e científicos da sociedade Nacional e demais sociedades indígenas e não indígenas; Garantir Alfabetização, Letramento e Numeramento aos AváCanoeiro de acordo com os direitos de aprendizagem na 
língua materna, língua portuguesa e demais línguas de seu interesse; Garantir igualdade de condições para o acesso e a permanência na escola, vedada qualquer forma de discriminação e segregação; Promover liberdade de aprender, ensinar, pesquisar e divulgar os saberes indígenas; Garantir gratuidade do ensino; Garantir o respeito e a valorização dos profissionais da Educação Escolar Indígena; Promover gestão democrática e colegiada da escola mediante regularização; Garantir os princípios da educação intercultural, considerando as experiências dos saberes indígenas e não indígenas, na perspectiva da diversidade histórico-sociocultural, linguística e de identidade AváCanoeiro; Promover o desenvolvimento físico, mental e efetivo no processo de educação e Promover a interação e o diálogo da educação escolar com a comunidade (PPP, 2016).

Sobre a elaboração do PPP da Escola Indígena Ikatoté, Niwatima AváCanoeiro, diretora, disse que:

Foi trabalho de todos nós, índios, amigos, seduce. Teve reunião para falar como a gente queria a escola, eu participei, meu irmão Trumak. Não é a mesma escola de Minaçu onde a gente estudou, aqui é nossa escola, do nosso jeito, da nossa cultura, pode colocar o que nos achar importante. Foi assim que vez, eu queria estudar palavras de Avá-Canoeiro, melhorar nossa língua que tá perdendo tudo, sumindo. A gente teve ajuda e agora temos escola. (RODA DE CONVERSA, 2019).

O Colégio Estadual Avá-Canoeiro Ikatoté contempla ainda o respeito às diversas formas de ensinar e aprender, sobretudo, valorizando os espaços de aprendizagens referenciados por Silva e Silva (2018, p.152). Para os autores os espaços de aprendizagens são:

Os diferentes espaços e tempos educativos, para os AváCanoeiro, estão além do espaço/tempo escolar disciplinar, compõem também espaços de aprendizagens - caçar na mata, pescar, coletar, preparar a roça, confeccionar artesanatos, fazer a pintura corporal, participar de palestras, oficinas e eventos dentro e fora da aldeia, brincar, desenhar, realizar passeios na casa dos moradores vizinhos, realizar viagens, nas rodas de conversa e reuniões, entre outros.

Nesse contexto, Silva e Silva (2018, p.152), consideram ainda que: "As atividades executadas na escola, elaboradas pelos professores, reforçam a importância dos espaços de aprendizagem, os quais contemplam o cotidiano da vida indígena, seus múltiplos saberes e formas de aprender".

São exemplos de espaços de aprendizagens para os Avá-Canoeiro: 
os arredores das casas; a roça e suas atividades; as coletas pelo Cerrado; a pesca; a varanda das casas; as idas na cidade de Minaçu; as visitas em vizinhos próximos; o banhar no rio; o preparo dos alimentos; a caça; a preparação e a pintura corporal; a confecção de artesanatos, objetos, brinquedos, tapetes; entre outros. Como mostra a figura 01 :

Figura 2 - Imagens de espaços de aprendizados na aldeia do povo Avá-Canoeiro e na Escola Ikatoté

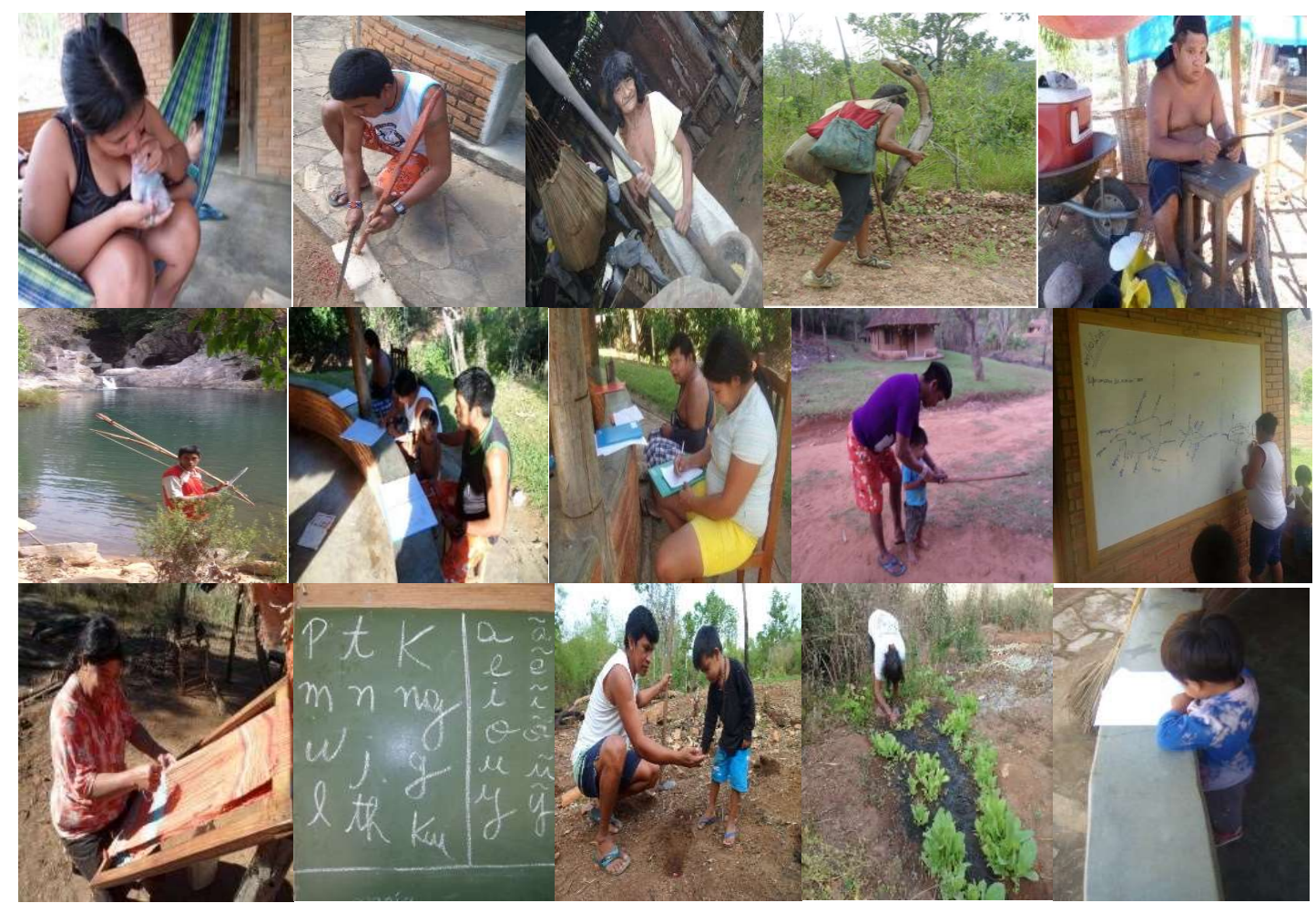

Fonte: Lorrane Gomes da Silva. Acervo da Tese (2016) e Trabalhos de campo $(2018,2019)$.

Para Parazinho Tapirapé, que é aluno da escola e marido de Niwatima Avá-Canoeiro:

A escola é também parte do que fazemo, tem dia que as crianças não querem ir, eu explico a importância de estudar. Eu dei aula aqui tem uns dias atrás para o Patxeo saber como planta milho, ele participou comigo até o fim e expliquei como faz cada coisa. A roça é importante para nós, as crianças tem que sabê. Quando a gente não tiver mais aqui, eles tem que saber sobreviver. Português para mim é difícil, mas não tem só isso, estou aprendendo a língua da minha esposa também. (RODA DE CONVERSA, 2019).

O plurilinguismo tem também sido respeitado na escola: as crianças são trilíngues estudam o português, a língua materna da mãe (Avá-Canoeiro) e a língua paterna do pai (Tapirapé), e mostram interesse 
em aprender outras línguas. Busca-se, com isso, fortalecer também o uso da língua Tapirapé entre seus falantes na Terra Indígena Avá-Canoeiro, almejando uma relação simétrica entre as três línguas que são utilizadas na aldeia. Segundo os estudos de Borges; Leitão (2003) e Silva (2014), é fundamental buscar uma relação simétrica entre línguas e contextos de uso, uma vez que se nota a força da língua portuguesa em relação assimétrica, frente ao uso das línguas indígenas no contexto da aldeia. Trumak Avá-Canoeiro, aluno da escola, disse que:

Eu sei falar Karajá um pouco, Tapirapé um pouco, Português e Avá-Canoeiro, mas é tudo difícil tem que querer. Eu quero estudar para tirar a carteira e ser motorista de caminhão. Já sei muitas palavras em português, escrever, mas tenho que sabê, mais, muito difícil. (RODA DE CONVERSA, 2019).

Por muitos anos tiveram muitas dificuldades de adaptar a escolas regulares. Com isso criou-se uma rejeição, sobretudo, do Trumak AváCanoeiro por escolas e professores de Minaçu. Como já dito, os AváCanoeiro são um povo que resistiu a muitas situações de violência, escassez, mudanças, o que gerou muitos traumas. Qualquer atividade voltada a eles requer preparo, conhecimento mínimo da cultura e das realidades vividas, e exige um tempo de adaptação maior.

Mesmo que a escola seja indígena, criada por eles e que atenda a organização sociocultural desse povo, há ainda muitos entraves para uma educação diferenciada se concretizar no Brasil e em Goiás. A burocracia para contratos, documentos, calendário, frequência, diários entre outras, é a mesmo do modelo da educação regular. Desse modo, se na construção da matriz e PPP a escola ganha características particulares e respeita a cultura indígena, por outro, há situações inconcebíveis ainda na prática no que tange às normas da Secretaria de educação do Estado.

Como inserir as festas culturais no calendário acadêmico? Como respeitar horários e momentos das atividades cotidianas sem interferir nas atividades da escola? Como oferecer lanche adequado? Como contabilizar presenças em aulas com contextos e espaços de aprendizagens diferenciados? Como elaborar diários com a rigidez de conteúdos, diante uma matriz curricular específica? Como elaborar materiais, conteúdos adequados que atenda às necessidades desse povo? Esses, entre outros, são desafios para adequação institucional das Escolas Indígenas não apenas em Goiás, mas no país.

Outro problema mencionado nas falas dos indígenas, foi que é preciso que tenha na Escola Ikatoté pelo menos uma professora da língua portuguesa - esse contrato tem sido feito com um acordo entre a SEDUC (paga o salário da professora) e a FUNAl (paga o combustível e deslocamento da professora de Minaçu para a escola). O contrato da professora tem sido firmado pela SEDUC. Porém, a contra partida da FUNAI não é regular, o que dificulta. Disse uma das professoras contratadas pela SEDUC que trabalha com os Avá-Canoeiro: 
Gosto demais do que faço, me esforço, estudo, para fazer o melhor para os Avá-Canoeiro, não é qualquer professor que aceita deslocar para aldeias ou comunidades distantes, eu não vejo problemas. Difícil é saber se terá alguém para me levar ou não e sempre é essa instabilidade. Enquanto isso, quem perde são eles, os índios. Eu estou sempre à disposição para realizar meu trabalho e nem posso falar nada, porque é delicado as situações. (RODA DE CONVERSA, 2019).

Os desafios são diários e há ainda muitos avanços a serem feitos. Nas falas dos indígenas, a importância da escola na aldeia é inegável, assim como também é inegável a importância da Educação Escolar indígena para o fortalecimento sociocultural desse povo, pois ela é uma ferramenta que pode contribuir para a autonomia e gestão de seus recursos e vidas. Espera-se que essa escola não morra, sem justificativas, no silenciar do tempo, como foram os demais processos de educação propostos no passado.

\section{Considerações Finais}

De acordo com o último Censo Escolar de 2018 , existem no Brasil 3.345 escolas indígenas de educação básica. Na comunidade escolar, os indígenas brasileiros correspondem a 255.888 estudantes e 22.590 professores.

Diante desse cenário, o povo Avá-Canoeiro tem direito, assim como os demais povos indígenas, a uma educação que respeite sua diversidade linguística e garanta a criação de espaços pluriepistemológicos, pautados na interculturalidade crítica que considere seus saberes e suas narrativas que foram violentamente negligenciadas e subalternizadas.

Ainda que a legislação educacional do país afirme o direito dos povos indígenas a uma educação específica, diferenciada, intercultural e multilíngue, com calendários diferenciados e a partir de propostas político-pedagógicas próprias, na prática é o modelo da escola nacional/disciplinar que continua se impondo. Esse cenário evidencia a existência de direitos formais que são negados e desrespeitados.

Este texto mostrou a negação ao direito à educação vivenciada pelo povo Avá-Canoeiro. As primeiras iniciativas, ainda tendo como base uma educação etnocêntrica, disciplinar e impositiva, mostram a discrepância entre o que determina as políticas educacionais indígenas mencionadas nas leis e a efetivação da prática vigente da Educação Escolar Indígena.

Destaca-se nesta pesquisa que, mesmo com a arrecadação de royalties e repasses financeiros altos de Furnas, os Avá-Canoeiro tiveram negado o acesso e o direito à Educação Escolar Indígena por décadas.

Contudo, apesar do Colégio Estadual Avá-Canoeiro Ikatoté ser ainda uma extensão e das experiências educacionais serem recentes, é evidente a contribuição da Educação Escolar Indígena para o povo Avá- 
Espaço Ameríndio

Canoeiro, que resiste pela permanência em seu território, pela reprodução sociocultural da vida indígena, em um grupo tão reduzido, que tem nas crianças a esperança em um futuro para continuar a resistir/existir. 
Espaço Ameríndio

\section{Referências bibliográficas}

ALMEIDA, Maria Geralda de. A captura do Cerrado e a precarização de territórios: um olhar sobre sujeitos excluídos. ALMEIDA, Maria Geralda. (Org) Tantos Cerrados. Goiânia: Vieira, 2005.

BARBOSA, Altair Sales; SCHMITZ Pedro Ignácio; Antônio NETO, Teixeira; GOMES Horieste. O piar da Juriti pequena: narrativa ecológica da ocupação humana do Cerrado. Publicado pela PUC/Goiás, 2014.

BHABHA, Homi K. o local da cultura. Belo Horizonte: Ed. UFMG, 1998.

BORGES, Mônica Veloso; LEITÃO, Rosani Moreira. O papel da Etnografia e da Linguística em projetos de educação indígena: o caso Avá-Canoeiro. Comunicação apresentada no Seminário do Grupo de Estudos sobre Relações Interétnicas, realizado na Universidade de Brasília, no Departamento de Antropologia, (mimeo), em 17 de janeiro de 2003.

BORGES, Mônica Veloso. O estudo do Avá: relato e reflexões sobre a análise de uma língua ameaçada de extinção. Revista Liames, Campinas, n. 2, p. 85-104, 2006.

CANDAU. Vera Maria Ferrão. Diferenças Culturais, Interculturalidade E Educação Em Direitos Humanos. Educ. Soc., Campinas, v. 33, n. 118, p. 235-250, jan.-mar. 2012.

CONTROLADORIA GERAL DA UNIÃO (CGU). Disponível em: http://www.cgu.gov.br/. Acesso: maio, 2019.

CONSTITUIÇÃO FEDERAL DE 1988. Disponível em: http://www.planalto.gov.br/ccivil 03/Constituicao/Constituicao.htm. Acesso: agosto, 2019.

CUNHA, Manoela Carneiro da. O futuro da questão indígena. Estudos Avançados 8 (20), 1994.

Diretrizes da Educação Escolar Indígena de 1998. Disponível em: http://portal.mec.gov.br/cne/arquivos/pdf/1999/pceb014 99.pdf. Acesso: agosto, 2019. FUNAI. Fundação Nacional do Índio. Relatório de Identificação e Delimitação da Terra Indígena Avá-Canoeiro. Não publicado. Processo nº253/1983.

Diretrizes da Educação Escolar Indígena de $1998 .$. http://www.funai.gov.br/index.php/indios-no-brasil/quem-sao. Acesso: 15.05.2019. IBGE. https://www.ibge.gov.br. Censo Demográfico (2010). Acesso: 15.05.2019.

GALLOIS, Dominique. 2005. 'Os Wajãpi em frente da sua cultura'. In Revista do patrimônio histórico e artístico nacional, v. 32, p. 110-129, 2005.

GOLDENBERG Mirian. A arte de pesquisar: como fazer pesquisa qualitativa em ciências sociais. Rio de Janeiro: Recorde. 1997. 
Espaço Ameríndio

HARRISON, Carl. Relatório Avá-Canoeiro. Brasília: SIL, (Arquivo Linguístico $\mathrm{n}^{\circ}$ 020), 1974.

LEI DE DIRETRIZES E BASES (93.94/96). Disponível em: http://portal.mec.gov.br/seesp/arquivos/pdf/lei9394_ldbn1.pdf. Acesso: agosto, 2019.

LÜDKE, M.; ANDRÉ, M. E. D. A. Abordagens qualitativas de pesquisa: a pesquisa etnográfica e o estudo de caso. In: Pesquisa em educação: abordagens qualitativas, São Paulo: EPU, 1986.

MALVEZZI, Roberto. Hidronegócio. In: CALDART, Roseli Salete, PEREIRA, Isabel Brasil, FIRGOTTO, Gaudêncio. Dicionário de Educação do Campo. Rio de Janeiro São Paulo: Expressão Popular, 2012, p. 397-404.

MARTINS, Joel. A pesquisa qualitativa. In: FAZENDA, I. (Org.). Metodologia da pesquisa educacional. São Paulo: Cortez, p. 47-58, 1989.

MEC (Ministério da Educação), Brasil. Censo Escolar Indígena. Sexta-feira, 19 de abril de 2019, 10h00. Disponível em: http://portal.mec.gov.br. Acesso: 14.08.2020.

MOURA, Adriana Ferro; LIMA, Maria Glória. A Reinvenção da Roda: Roda de Conversa, um instrumento metodológico possível. Revista Temas em Educação, v. 23, n. 1, p. 95-103, 2014.

MOURA, Marlene Castro Ossami de. (Coord.). Índios de Goiás: uma perspectiva Histórico-Cultural. Goiânia: Ed. da UCG; Ed. Vieira; Ed. Kelps, 2006.

MINAYO, Maria Cecília de Souza (org.). Pesquisa Social. Teoria, método e criatividade. 18 ed. Petrópolis: Vozes, 2001.

NAZARENO, Elias. Revisitando o debate acerca da Modernidade a Partir da Colonialidade do poder e da Decolonialidade. Revista Nós, v. 03, p. 27-45, 2017.

NAZARENO, Elias. História, tempo e lugar entre o povo indígena Bero Biawa Mahãdu (Javaé): a partir da interculturalidade crítica, da decolonialidade e do enfoque enactivo, Unila, 2016.

OLIVEIRA, R. Cardoso de. O trabalho do antropólogo: olhar, ouvir, escrever. 2. Ed. Brasília: Paralelo 15; São Paulo: Editora UNESP, 17-35 p, 2000.

PARECER 14/99 DO CONSELHO NACIONAL DA EDUCAÇÃO. Disponível em: http://portal.mec.gov.br/sesu/arquivos/pdf/leis2.pdf. Acesso: agosto, 2019.

PEDROSO, Dulce Madalena Rios. O Povo Invisível: a história dos avá-canoeiros nos séculos XVII e XIX. Goiânia: Editora PUC/Goiás, 1994.

PEDROSO, Dulce Madalena Rios. Avá-Canoeiro: A história do povo invisível - Séculos XVIII e XIX. 1992. Dissertação (Mestrado em História das Sociedades Agrárias) Instituto de Ciências Humanas e Letras, Universidades Federal de Goiás, Goiânia, 1992. 
Espaço Ameríndio

PROJETO POLÍTICO PEDAGÓGICO, Escola Ikatoté, Município de Minaçu, Goiás, Terra Indígena Avá-Canoeiro, Documento em elaboração. Não publicado, 2019.

RESOLUÇÃO $\mathrm{N}^{\mathrm{o}} 5$ DE 2012 DA EDUCAÇÃO. Disponível em: http://portal.mec.gov.br/secretaria-de-regulacao-e-supervisao-da-educacao-superiorseres/323-secretarias-112877938/orgaos-vinculados-82187207/17417-ceb-2012. Acesso: agosto, 2019.

RODRIGUES, Aryon. D. Línguas Indígenas: 500 Anos de Descobertas e Perdas. DELTA, SAO PAULO, v. 9, n.1, p. 83-103, 1993.

RODRIGUES, Patrícia de Mendonça. Os Avá-Canoeiro do Araguaia e o tempo de cativeiro. In: Anuário Antropológico, 2013.

SCHMITZ, Pedro Ignacio; WÜST, Irmhild; COPÉ, Silvia Moehlecke; THIES, U.M.E. Arqueologia do Centro-Sul de Goiás. Uma fronteira de horticultores indígenas no Centro do Brasil. Pesquisas, São Leopoldo, Antropologia no 33, 1982.

SILVA, Ariel Pheula do Couto e.; SILVEIRA, Ester Maria De Oliveira; GUEDES, Elisa. Diagnóstico da Educação Avá-Canoeiro: relatório de atividades e histórico do percurso educacional dos Avá- Canoeiro". (Relatório manuscrito, não publicado), resultado de uma consultoria, 2014.

SILVA, Cristian Teófilo. Cativando Maira: a sobrevivência Avá-Canoeiro no Alto Rio Tocantins. Tese de doutorado. Brasília. Faculdade de Antropologia Social, Universidade de Brasília, Brasília, 2005.

SILVA, Lorranne Gomes da Silva; SILVA, Ariel Pheula do Couto. Processos educacionais na Terra Indígena Avá-Canoeiro de Goiás: Panorama Histórico e perspectivas futuras. In: Artes Indígenas no Cerrado: saberes, educação e museus. BICALHO, Poliene Soares dos Santos; MACHADO, Márcia (orgs.). Coleção Tessituras do Cerrado. Editora da PUC, 2018.

SILVA, Lorranne Gomes da Silva. Singrar rios, morar em cavernas e furar jatoká: ressignificações culturais, socioespaciais e espaços de aprendizagens da família AváCanoeiro do Rio Tocantins. Tese (Doutorado em Geografia). Instituto de Estudo Sócioambientais - UFG, Universidade Federal de Goiás. Goiânia, 2016.

SOUZA LIMA, Antônio Carlos de. Um grande cerco de paz: poder tutelar, indianidade e formação do Estado no Brasil. Petrópolis (RJ): Vozes, p.191, 1995.

TORAL, André Amaral. Vocabulário Avá-Canoeiro (mimeo), 1984.

Recebido em: 17/09/2020 * Aprovado em: 22/01/2021 * Publicado em: 28/04/2021 